\title{
Urine screening by Seldi-Tof, followed by biomarker identification, in a Brazilian cohort of patients with Renal Cell Carcinoma (RCC)
}

Gilda Alves, Denise A. Pereira, Vanessa Sandim, Antonio A. Ornellas, Niko Escher, Christian Melle, Ferdinand von Eggeling

Applied Genetic Laboratory, Hematology Division, National Institute of Cancer, (GA, DAP, VS); Division of Urology, National Institute of Cancer, (AAO); Division of Urology, Hospital Mário Kroeff, Rio de Janeiro, RJ, Brazil (AAO); Core Unit Chip Application, Institute of Human Genetics, Jena University Hospital, Jena, (NE, FE); Alere Technologies GmbH, Jena, (NE) and Biomolecular Photonics Group, Jena University Hospital, Germany (CM)

\section{ABSTRACT}

Purpose: To screen proteins/peptides in urine of Renal Cell Carcinoma (RCC) patients by SELDI-TOF (Surface Enhanced Laser Desorption Ionization - Time of Flight) in search of possible biomarkers.

Material and Methods: Sixty-one urines samples from Clear Cell RCC and Papillary RCC were compared to 29 samples of control urine on CM10 chip. Mass analysis was performed in a ProteinChip Reader PCS 4,000 (Ciphergen Biosystems, Fremont, CA) with the software Ciphergen Express 3.0. All chips were read at low and at high laser energy. For statistical analysis the urine samples were clustered according to the histological classification (Clear Cell and Papillary Carcinoma). For identification urine was loaded on a SDS PAGE gel and bands of most interest were excised, trypsinized and identified by MS/MS. Databank searches were performed in Swiss-Prot database using the MASCOT search algorithm and in Profound.

Results: Proteins that were identified from urine of controls included immunoglobulin light chains, albumin, secreted and transmembrane 1 precursor (protein K12), mannan-binding lectin-associated serine protease-2 (MASP-2) and vitelline membrane outer layer 1 isoform 1. Identification of immunoglobulins and isoforms of albumin are quite common by proteomics and therefore cannot be considered as possible molecular markers. K12 and MASP-2 play important physiological roles, while vitellite membrane outer layer 1 role is unknown since it was never purified in humans.

Conclusions: The down expression of Protein K-12 and MASP-2 make them good candidates for RCC urine marker and should be validated in a bigger cohort including the other less common histological RCC subtypes.

\section{ARTICLE INFO}

\section{Key words:}

Carcinoma, Renal Cell;

Biological Markers;

Proteomics;Proteins; MASP2

protein, human

[Supplementary Concept]

Int Braz J Urol. 2013; 39: 228-39

Submitted for publication:

May 10, 2012

Accepted after revision:

November 11, 2012

\section{INTRODUCTION}

Urine analysis is a non-invasive method of clinical analysis and has been used primarily to monitor diseases of the urogenital tract. In a pe- riod of 24 hours, normal urine shows 150 milligrams of proteins and peptides that are derived from a variety of sources. Most of them come from the glomerular filtrate of plasma, while others from 
the process of apoptosis and the cleavage of membrane proteins that are secreted. High molecular weight proteins (albumin, for example) are able to pass through the glomerular filtrate. Small proteins, or peptides $(<10 \mathrm{kDa})$ are easily filtered by the glomerulus and constitute an important source of information, even if the peptide is the result of proteolysis of larger proteins circulating in plasma (1-3). Urine is especially attractive for biomarker discovery in urological diseases since any change in concentration of proteins in plasma will reflect in the urine.

Mass Spectroscopy (MS) is an analytical technique that measures the mass-to-charge ratio of charged particles. It is used for determining the composition of a sample or molecule, and for elucidating the chemical structures of molecules, such as peptides and other chemical compounds. MS works by ionizing chemical compounds; the ions are then accelerated through a potential difference and focused into a beam. The ion beam passes through a magnetic field which bends the charged stream. Lighter components or components with more ionic charge will deflect in the field more than heavier or less charged components. The final element of a MS is the detector. The detector records either the charge induced or the current when an ion passes by or hits a surface. In a scanning instrument, the signals will generate a mass spectrum, a record of ions expressed as $\mathrm{m} / \mathrm{z}$ (mass/charge).

MS/MS is the tandem mass spectrometry consisting of two mass spectrometers in series connected by a chamber known as a collision cell. The sample to be examined is essentially sorted and weighed in the first mass spectrometer, then broken into pieces in the collision cell, and a piece or pieces sorted and weighed in the second mass spectrometer. Identification by MS/MS is considered more accurate.

The technology of SELDI-TOF (Surface Enhanced Laser Desorption Ionization - Time of Flight) is a kind of mass spectrometer (MS). The instrument enables the separation of proteins and peptides by their physical properties (hydrophobic, hydrophilic, acidic, basic, with affınity for metal etc.) on a solid surface called Chip. The time-of-flight (TOF) analyzer measures the time they take to reach the detector. Ions velocities will depend on their masses and lighter ions will reach the detector first. The SELDI-TOF is very sensitive instrument and is able to detect proteins in fluids like urine without previous processing.

In spite of some new drugs for treatment (4), RCC is a disease that would benefit from improvement of early detection. More than 30\% of patients show locally advanced or metastatic disease at diagnosis. Furthermore, approximately $40 \%$ of patients undergoing curative surgery for localized disease relapse. In search of possible biomarkers, we have screened proteins/peptides in individual samples of urine from 61 RCC Brazilian patients of the two most common histological subtypes (Clear Cell (CC) and Papillary).

\section{MATERIAL AND METHODS}

\section{Patients and Controls}

Patients and control individuals included in this study were adults of both genders, smokers and nonsmokers. This study was approved by the Ethics Committee of Instituto Nacional de Câncer (INCA), Rio de Janeiro, Brazil, registration \# 38/05.

Urine samples were obtained from 61 untreated adult patients attending to the Departments of Urology of Instituto Nacional de Câncer and Hospital Mário Kröeff. Histological classification followed WHO guidelines. Table-1 shows the histological data as well as patient gender, Fuhrman grade, stage, follow-up and outcome. We were unable to establish the Fuhrman grade in a patient with papillary RCC type I. Patient follow-up data were gathered from medical charts and when necessary through contact with the patient family. We retrospectively reviewed the charts to determine dates of recurrence and death, as well as cause of death. Mean and median patient age was 59 and 55 years at diagnosis (range 27 to 84), respectively. Follow-up was evaluated in 61 patients. Median follow-up was 38 months (range 1 to 75). Patients with genetic syndromes or mental illness or immunodeficiency or who have been treated for cancer before were excluded from this study. Other exclusion criteria were the presence of proteinuria, microalbuminuria (diabetes mellitus), auto immune 


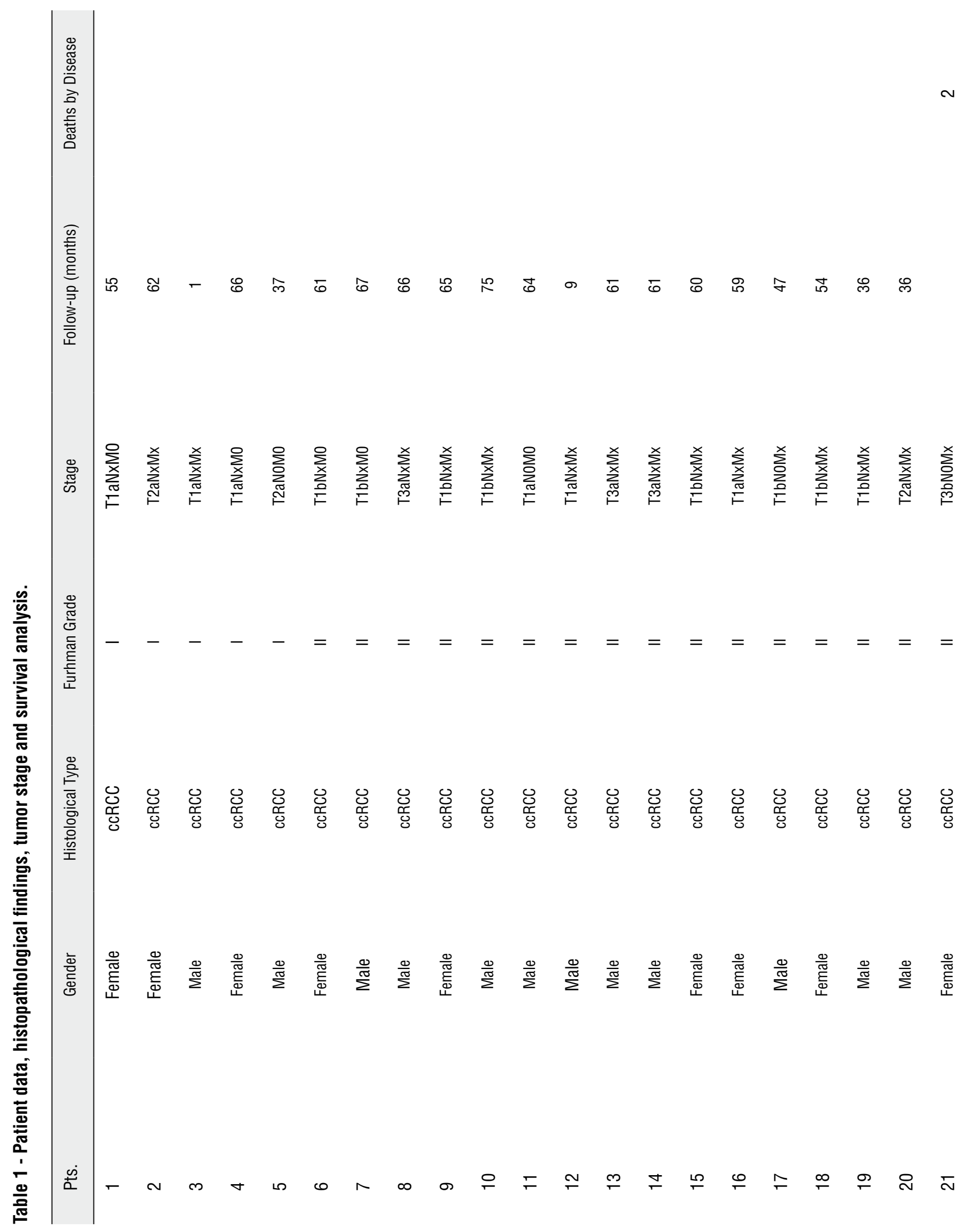




$$
\begin{aligned}
& \text { ○ } \quad \text { in } \\
& \text { న }
\end{aligned}
$$

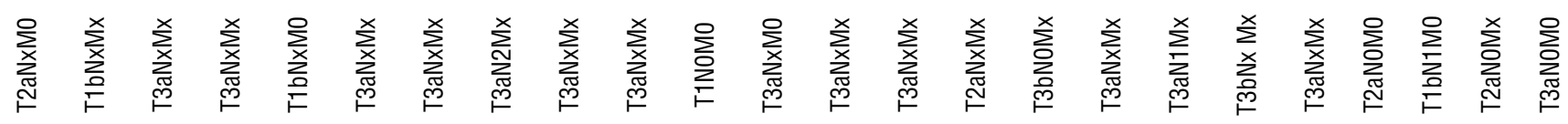

$$
\begin{aligned}
& ====\equiv \equiv \equiv \equiv \equiv \equiv \equiv \equiv \equiv \equiv \equiv \equiv \equiv \equiv \equiv \equiv \equiv
\end{aligned}
$$

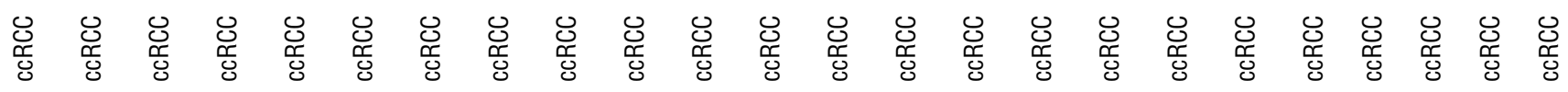

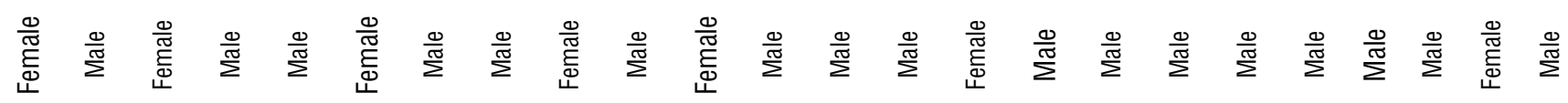

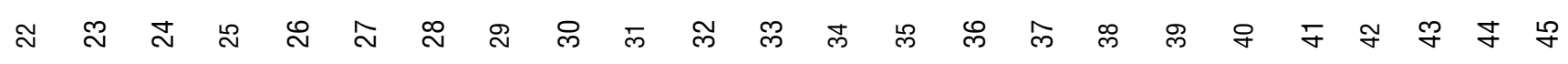




$$
\begin{aligned}
& 0 \approx 0 \quad \text { ก } \\
& \text { ర시 - }
\end{aligned}
$$

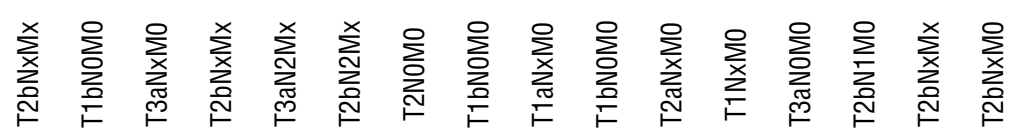

$$
\begin{aligned}
& \geq \geq \geq \geq \geq \geq \geq \geq ;====\equiv
\end{aligned}
$$

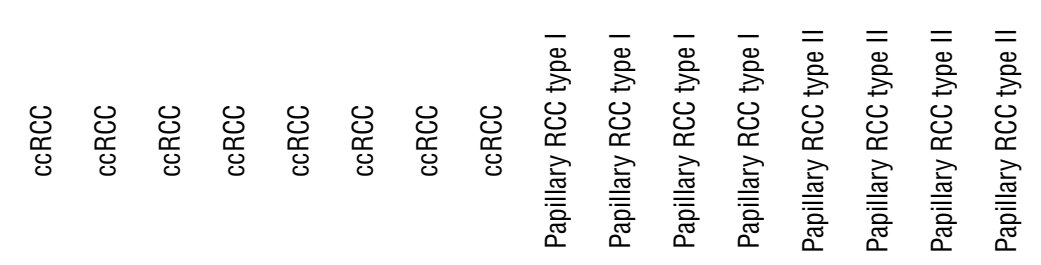

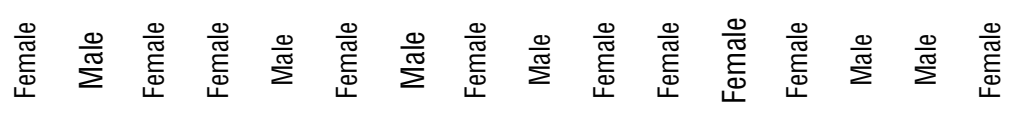

우 少 守 
glomerulopathies, chronic kidney disease, urinary tract infections, lithiasis and prostatic diseases.

Twenty-nine control urine samples were obtained from over 40 years old healthy individuals from Laboratory of Molecular Biology, Department of Urology, Jena University Hospital, Germany. Control individuals had no indications of kidney abnormalities.

\section{Urine Collection}

The 10-20 mL first-void urine was discarded; the following 50-70 mL urine was collected, centrifuged at $1,000 \mathrm{~g}$ for 10 minutes and the supernatant saved (5). Phenylmethanesulfonyl fluoride (PMSF) was added to the urine samples at final concentration of $1 \mathrm{mM}$, aliquoted and frozen at $-70^{\circ} \mathrm{C}$.

Binding conditions of urine proteins to the chips

Aliquots of urine were thawed in ice and were then vortexed at full power (6). Thereafter, all procedures were carried out at room temperature. All experiments were performed in duplicate. Three kinds of chips, IMAC30, Q-10 and CM10 (BIORAD), were tested.

The operating mechanism of the ProteinChip IMAC30 is the reversible binding of proteins to the surface through a coordinated metal interaction. The ProteinChip IMAC30 array incorporates nitrilotriacetic acid (NTA) groups and is capable of forming stable octahedral complexes with polyvalent metal ions, including $\mathrm{Cu} 2+, \mathrm{Ni} 2+, \mathrm{Fe} 3+$, and Ga3+. After loading the array surface with the desired metal ion, two free sites are available from the formed octahedral complex for interaction with specific amino acid residues (such as His) or posttranslational modifications such as phosphate groups. To generate selectivity, binding and washing buffers may contain increasing concentrations of competitors, such as imidazole, which compete with the coordinated metal on the NTA group for binding to the protein or peptide.

Q10 incorporates quaternized ammonium groups (positively charged) and thus acts as a strong anion exchanger. The Q10 surface binds peptides and proteins that are negatively charged at a given $\mathrm{pH}$. By maintaining the $\mathrm{pH}$ of the binding or washing buffer at alkaline conditions (e.g.,
$\mathrm{pH}$ 8), an overall net negative charge is imparted on a greater number of proteins within the sample (therefore more binding). By decreasing the $\mathrm{pH}$ of the binding or washing buffer, an overall net positive charge is imparted on the proteins, resulting in less binding (i.e., more specificity).

CM10 incorporates a carboxylate chemistry (negatively charged) and thus acts as a weak cationic exchanger. CM10 surface binds proteins that are positively charged at a given $\mathrm{pH}$. To generate selectivity, the $\mathrm{pH}$ of the binding buffer is increased or decreased, depending on the need. By decreasing the $\mathrm{pH}$ of the binding and washing buffers, an overall net positive charge is imparted on a greater number of proteins within the sample (therefore more binding). By increasing the $\mathrm{pH}$ of the binding and washing buffers, an overall net negative charge is imparted on the proteins, resulting in less binding (i.e., more specificity).

The effect of prefractioning of the urine samples was tested applying the Protein Chip Serum Fraction kit (BioRad, cat. K10-0007) according to manufacture's protocol. The increase of the peak intensity was also tested with the addition of a denaturing solution (9M urea, 2\% CHAPS (3-[(3-Cholamidopropyl) dimethylammonio]-1-propanesulfonate hydrate), 50mM TRIS (Tris (hydroxymethyl)aminomethane)-HCl $\mathrm{pH}$ 9.0) to the urine before mixing to the binding buffer.

Alternatively, $50 \mu \mathrm{L}$ of pure urine were loaded with appropriate buffers in a bioprocessor (Ciphergen) for 90 minutes on a shaker. The chips were then washed, on a shaker, three times with the same buffers and two times with deionized water and air dried. A saturated solution of sinapinic acid (SPA) was prepared and $2 \times 0.5 \mu \mathrm{L}$ was applied in each spot. Figure-1a shows the assembling of chips into a frame that will go into a bioprocessor (Figure-1b); Figure-1c shows a chip being inserted into the SELDI-TOF).

Spectral data processing and statistical analysis Pure urines from 29 cases of low grade ccRCC (Fuhrnann grade I + II), 24 from high grade ccRCC (Fuhrnann grade III + IV), 8 from were Papillary RCC (Fuhrnann grade II + III + IV) and 29 controls were individually analyzed in a ProteinChip Reader PCS 4,000 (Ciphergen Biosyste- 
Figure $1 \mathrm{~A}-\mathrm{C}$ - Assembling of chips into the bioprocessor and insertion of a chip into the SELDI-TOF.
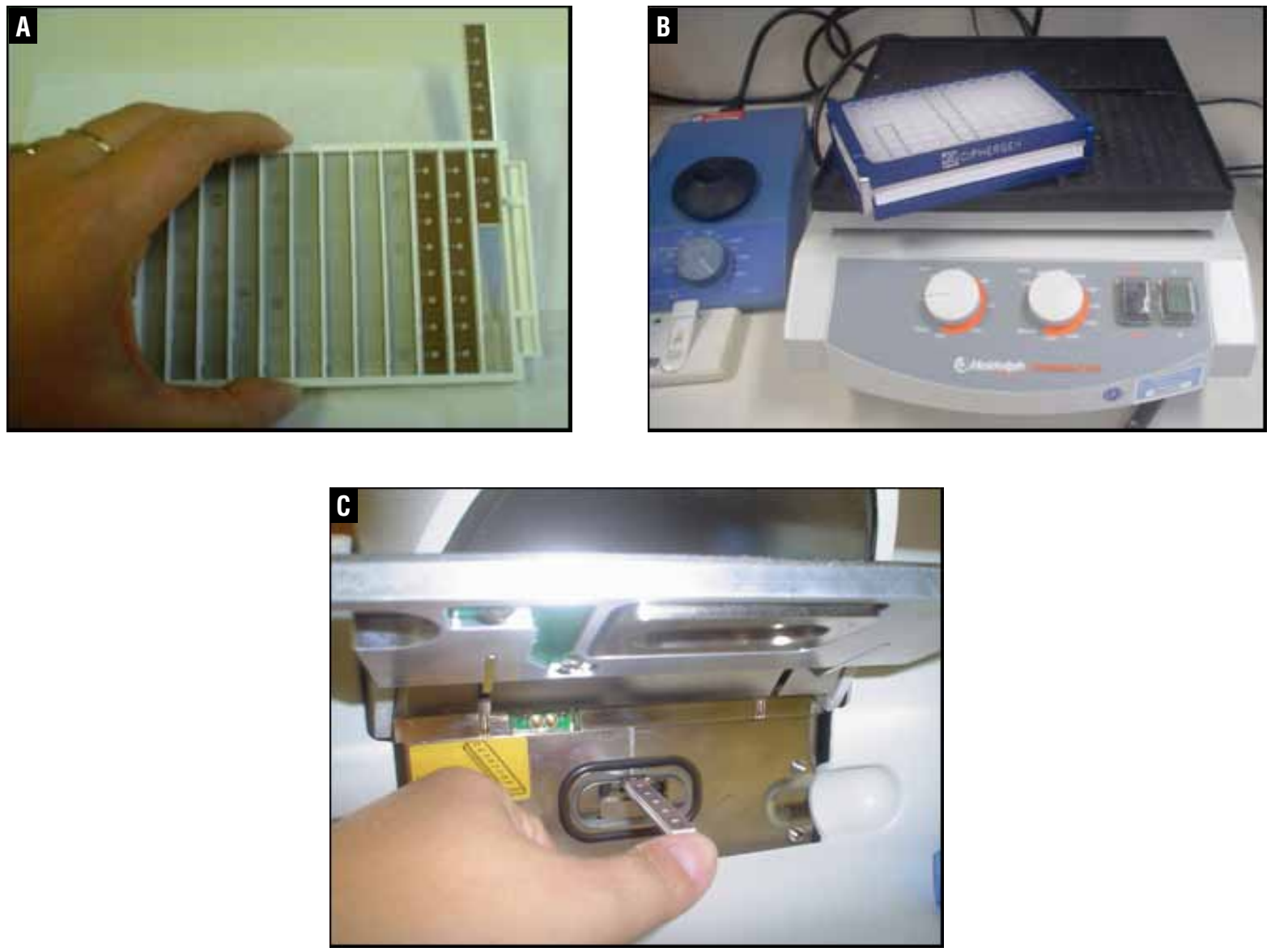

ms, Fremont, CA) with the software Ciphergen Express Client 3.0. All chips were read at low laser energy $(2,200 \mathrm{KJ})$ and at high laser energy $(3,500 \mathrm{KJ})$. Low laser energy and high laser energy focused mass range $(\mathrm{m} / \mathrm{z})$ of 1,000 to 20,000 Da and 20,000 to 200,000 Da, respectively. Peaks corresponding to albumin and hemoglobin were excluded from the analysis.

Urine pool fractionation with RP beads followed by SDS page gel

$\mathrm{RP}$ resins are a family of polymeric media useful for sample fractionation. RP beads are porous spherical beads, containing a surface area that is chemically stable to maximize extraction efficiency. The beads resin shows special characte- ristics such as: non-polar, non-ionic, ultra-clean, highly crossed-linked polymers that differ in particle size, pore size and surface area. The pore size large is selected according elements to enter into the pore and to adsorb onto the pore surface. Among the applications are exchange solvents, separate hydrophobic molecules by size and desalt samples.

Twenty $\mathrm{mL}$ of pooled urine from the control group were used for this experiment and mixed with $200 \mu \mathrm{L}$ of equilibrated RP beads (Polymer

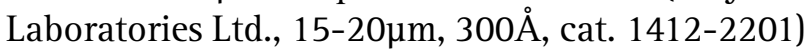
that were equilibrated in 10\% acetonitrile/0.1\% trichloroacetic acid. After 30 minutes incubation with mixing, the sample was centrifuged at $1,500 \mathrm{~g}$ for 8 minutes and the supernatant was discarded. 
The sample was fractionated into six fractions by sequential elution with $100 \mu \mathrm{L}$ aliquots of elution buffer with increasing concentrations of acetonitrile in $0.1 \%$ trichloroacetic acid (10-100\% acetonitrile). Two $\mu \mathrm{L}$ of each fraction was directly spotted on the CM10 and analyzed by SELDI-TOF for selection. The fraction containing the protein of interest was concentrated in a vacuum centrifuge and loaded on a precast 12\% SDS-PAGE gel (Invitrogen). Protein fractions co-migrated with the molecular maker Page Ruler Plus (Fermentas, cat. SM 1811). The gel was stained with Simply Blue Safe Stain (Enhanced Coomassie, Invitrogen).

\section{Gel band trypsinization}

The band of interest was excised from the stained gel and destained overnight with a mix of methanol 50\% and acetic acid 10\%. The gel piece was dehydrated in 100\% acetonitrile for $30 \mathrm{mi}$ nutes, dried in a vacuum centrifuge. Ten $\mathrm{ng} / \mathrm{mL}$ of sequencing grade trypsin (Promega, UK) in 50 $\mathrm{mM}$ ammonium bicarbonate was added to dried gel piece and incubated at $37 \mathrm{oC}$ overnight.

\section{MS/MS Analysis}

The resulting peptides were analyzed in a MALDI TOF/TOF with a Bruker ultraflex device (Bruker Daltonics, Bremen, Germany). Briefly, samples were prepared in dried-droplet-preparation with $\alpha$-hydroxy-cyano-cinnamic acid (CHCA). Peptide mass fingerprint and peptide fragmentation spectra of each sample were sub- mitted for identification using MASCOT interface (MASCOT inhouse server 2.1.03, Matrix Science, London, UK) for search in the NCBI database. Hits were considered significant according to the MASCOT score $(P=0.05)$.

\section{RESULTS}

\section{Binding conditions to the chips}

Tests were performed with 3 different chips (IMAC30, Q-10 and CM10, BIORAD). The quantity of peaks that were produced in each condition was considered. The protocol applying fractions produced by the Protein Chip Serum Fraction kit did not improve the number of peaks and their intensity, no matter the chip. The protocol of pre-denaturing of the urine has not improved the results as well. The highest number of peaks were generated when pure urine samples were applied on CM10 chip therefore it was selected to perform the screening of RCC urines.

\section{Peaks selection and identification}

For analysis, the urine samples were clustered according to the histological classification and compared to 29 control samples. We observed 22 peaks $(\mathrm{m} / \mathrm{z})$ that were statistically overexpressed $(p<0.05)$ in the control group. The most significant peaks are listed at Table-2. An example of differently expressed peak is shown in Figure-2.

The selected RP fractions of the control urine pool were loaded in a SDS PAGE gel (Figure-3)

Table 2 - Peaks $(\mathrm{m} / \mathrm{z})$ found overexpressed in the Control urine group in comparison to different histological/grade types of Renal Cell Carcinoma (RCC) urines.

\begin{tabular}{lcc}
\hline Groups compared & Peaks at Low Energy & Peaks at High Energy \\
\hline Control x low grade ccRCC & 9,772 & 23,622 \\
Control x high grade ccRCC & 4,751 & 23,615 \\
& 9,772 & 84,065 \\
Control x low + high grade ccRCC & 9,772 & 23,622 \\
Control x Papillary RCC & 9,097 & 23,615 \\
& 9,772 & 83,494 \\
\hline
\end{tabular}

ccRCC - Clear Cell Renal Cell Carcinoma 
Figure 2 - Spectra showing the peak of approximately 23,600 that is underexpressed in patients.

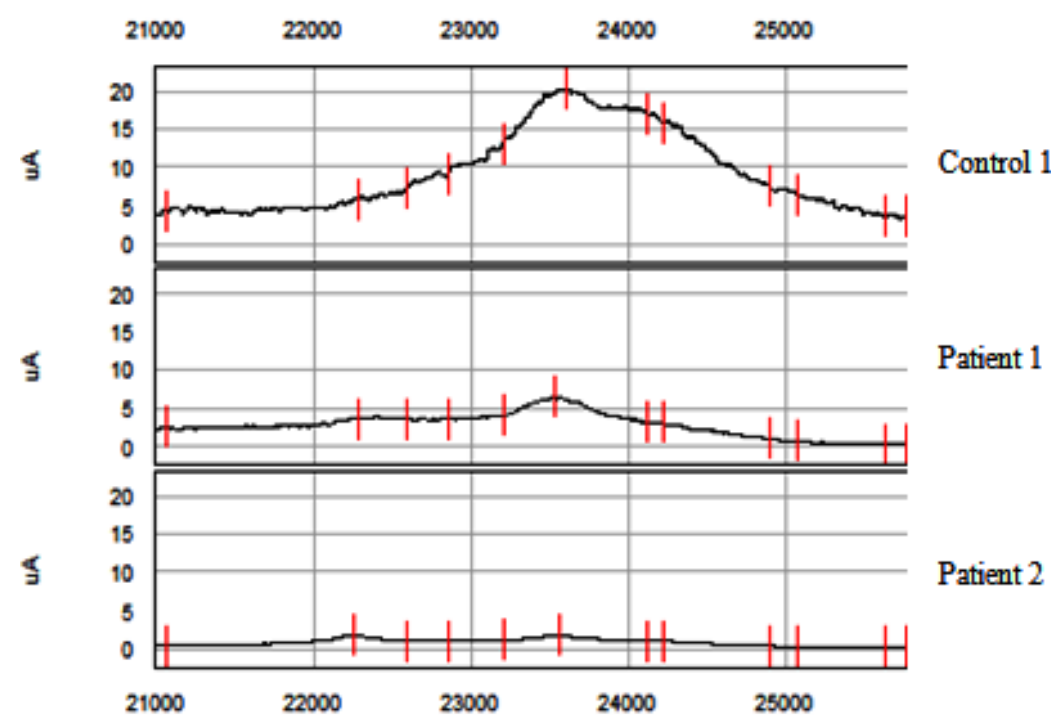

Figure 3 - Isolation of bands of interest from a Coomassie Blue stained $12 \%$ SDS PAGE gel from fraction eluted with $60 \%$ acetonitrile. Arrows indicate the bands of interest of approximately $9,770(A)$ and 23,600 (B). and bands of most interest (A and B) were excised for identification. Table 3 shows the results of the MS/MS analysis of bands A and B (Figure-3).

\section{COMMENTS}

The under detection of peaks in the urines of ccRCC and in Papillary RCC patients by SELDI-TOF screening was remarkable. This could be understandable by protein degradation in urine of these patients. The loss of proteins was noticed before by Sherief et al. (7) who reported that urinary extracellular matrix proteins laminin, collagen IV and fibronectin, which are known to be secreted by renal epithelial cells, were significantly decreased or absent in the urine specimens of patients with RCC. Corroborating to this, the metalloproteinase (MMP) activity was found higher in the urine of RCC patients (7). The elevated levels of MMP activity shall result in extracellular matrix proteins degradation that were either decreased or absent in the patients urines. Therefore, the explanation for the under detection of peaks reported herein could be due to protein degradation in the same way. Nevertheless, we cannot completely rule out that the results contain any bias due to the methods that were applied. 
Table 3 - Protein identified by MS/MS.

\begin{tabular}{|c|c|c|c|c|c|}
\hline Band & $\left.N C B\right|^{1}$ & Human Protein & Score $^{2}$ & $\begin{array}{c}\text { Average } \\
\text { mass }^{3}(\mathrm{KDa})\end{array}$ & Peptide $^{4}$ \\
\hline A & gi|306999 & $\begin{array}{l}\text { Immunoglobulin } \\
\text { light chain }\end{array}$ & 81 & & $\begin{array}{c}\text { R.LLIYGASTR.A } \\
\text {-.EIVLTQSPGTLSLSPGER.A }\end{array}$ \\
\hline A & gi|23241675 & Albumin & 195 & 46,442 & $\begin{array}{c}\text { K.FQNALLVR.Y } \\
\text { K.LVNEVTEFAK.T } \\
\text { K.KVPQVSTPTLVEVSR.N }\end{array}$ \\
\hline B & gi|4506869 & $\begin{array}{l}\text { Secreted and } \\
\text { transmembrane } 1 \\
\text { precursor }\end{array}$ & 113 & 27,307 & $\begin{array}{l}\text { R.DSHAGLYMWHLVGHQR.N } \\
\text { R.AHGQESAIFNEVAPGYFSR.D }\end{array}$ \\
\hline B & gi|3297879 & $\begin{array}{l}\text { MASP-2; mannan-binding } \\
\text { lectin-associated serine } \\
\text { protease-2 }\end{array}$ & 62 & 77,176 & R.APGKDTFYSLGSSLDITFR.S \\
\hline B & gi|32698964 & $\begin{array}{l}\text { Vitelline membrane outer } \\
\text { layer } 1 \text { isoform } 1\end{array}$ & 146 & 22,034 & $\begin{array}{l}\text { R.GLGDDTALNDAR.L } \\
\text { R.VEAPTTLGDNTAANNVR.F } \\
\text { K.VEPPQGIPGDDTALNGIR.L }\end{array}$ \\
\hline
\end{tabular}

${ }^{1} \mathrm{NCBI}$ : National Center for Biotechnology Information: numbering refers to the protein in database

${ }^{2} \mathrm{~S}$ core: ideal value is above 35

${ }^{3}$ Theoretical molecular weight;

${ }^{4}$ Representative peptides: trypic peptides in which the analyses were based.

Proteins that were identified from urine of controls by MS/MS analysis were immunoglobulin light chain, albumin, secreted and transmembrane 1 precursor (protein K12), mannan-binding lectin-associated serine protease-2 (MASP-2) and vitelline membrane outer layer 1 isoform 1 (Table-3). Identification of immunoglobulins and isoforms of albumin are quite common by proteomics and therefore cannot be considered as possible molecular markers. On the other hand, the other 3 identified proteins should be taken into consideration. The peptides sequences (Table-3) from each one of these proteins were checked on uniprot data bank (www.uniprot.org) and they all corresponded $100 \%$ to the proteins assigned.

Expression of mRNA of K12 gene (SECTM1) was detected at the highest levels in peripheral blood leukocytes and breast cancer cell lines. Western blots showed that the K12 protein exists as a cluster of bands around $27 \mathrm{kDa}$, and extractions using nonionic detergents or high $\mathrm{pH}$ conditions demonstrate that it behaves as an integral membrane protein. Immunofluorescence localization studies reveal that K12 is not detectable on the cell surface, but instead is found in a perinuclear Golgi-like pattern and colocalizes with a well-known Golgi marker. In addition, an approximately $20-\mathrm{kDa}$ soluble form of the K12 protein derived from the $\mathrm{N}$-terminal domain is specifically secreted by cells into the culture medium. Immunohistochemical analysis of peripheral blood cells shows that K12 is found in leukocytes of the myeloid lineage, with the strongest staining observed in granulocytes and no detectable expression in lymphocytes. Based on its range of expression, it is possible that $\mathrm{K} 12$ is a protein 
with potential importance in hematopoietic and/ or immune system processes (8).

Mannan-binding lectin (MBL) is an oligomeric serum lectin that plays a role in innate immunity by activating the complement system. In human, two types of MBL-associated serine protease (MASP-1 and MASP-2) and a truncated protein of MASP-2 (small MBL-associated protein; sMAP or MAp19) are complexed with MBL (9). After activation by auto-catalytic cleavage, MASP-2 cleaves $\mathrm{C} 2$ and $\mathrm{C} 4$, leading to their activation and to the formation of $\mathrm{C} 3$ convertase.

Vitelline membrane outer layer 1 isoform 1 belongs to the family VMO1 that is conserved in the chicken, in the mouse and in human. In chickens, this protein participates in the construction of the vitelline membrane portion of the egg shell, a rigid structure required to maintain the shape of the egg (10). The role of this protein in humans is unknown, actually it was never purified. It was inferred from electronic annotation and probably is secreted.

Amazingly, the down expression of protein K-12 and MASP-2 were observed in two histological subtypes (ccRCC and Papillary) which show differentiated origin in the kidney and distinguished genetics alterations. Papillary RCCs are characterized by trisomy of chromosomes $3 \mathrm{q}, 7,8$, $12,16,17$, and 20 and loss of the Y. On the other hand, chromosome $3 p$ deletion is the most typical genetic alteration in ccRCC, present in 75.8\% of cases which coincides with von Hippel-Lindau disease (11). This fact creates the possibility that a subtype independent RCC urine marker could be in the way. K-12 and MASP-2 should be tested in the urine of other RCC histological subtypes, although they are much less frequent than ccRCC and Papillary.

\section{CONCLUSIONS}

The down expression of Protein K-12 and MASP-2 make them good candidates for RCC urine makers and should be validated in a bigger cohort including the other less common histological RCC subtypes. Probably, these proteins were found in the control urine as a consequence of blood filtration role developed by the kidney. The lower abundance of these proteins in the patients' urine could be a consequence of their degradation or of kidney failure.

\section{ACKNOWLEGMENTS}

We thank Prof. Dr. Kestin Junker of Laboratory of Molecular Biology, Department of Urology, Jena University Hospital, 07740 Jena, Germany, for providing some of urine control samples and Annett Urbanek for technical assistance at SELDI-TOF.

This work was supported by PROBRAL CAPES/DAAD 293/08 and Programa de Oncobiologia (Rio de Janeiro, Brazil).

\section{CONFLICT OF INTEREST}

None declared.

\section{REFERENCES}

1. Rindler MJ, Naik SS, Li N, Hoops TC, Peraldi MN: Uromodulin (Tamm-Horsfall glycoprotein/uromucoid) is a phosphatidylinositol-linked membrane protein. J Biol Chem. 1990; 265: 20784-9.

2. Pisitkun T, Shen RF, Knepper MA: Identification and proteomic profiling of exosomes in human urine. Proc Natl Acad Sci U S A. 2004; 101: 13368-73

3. Pisitkun T, Johnstone R, Knepper MA: Discovery of urinary biomarkers. Mol Cell Proteomics. 2006; 5: 1760-71.

4. Ather MH, Masood N, Siddiqui T: Current management of advanced and metastatic renal cell carcinoma. Urol J. 2010; 7: 1-9.

5. Schaub S, Rush D, Wilkins J, Gibson IW, Weiler T, Sangster $\mathrm{K}$, et al.: Proteomic-based detection of urine proteins associated with acute renal allograft rejection. J Am Soc Nephrol. 2004; 15: 219-27.

6. Mataija-Botelho D, Murphy P, Pinto DM, Maclellan DL, Langlois C, Doucette AA: A qualitative proteome investigation of the sediment portion of human urine: Implications in the biomarker discovery process. Proteomics Clin Appl. 2009; 3: 95-105.

7. Sherief MH, Low SH, Miura M, Kudo N, Novick AC, Weimbs $\mathrm{T}$ : Matrix metalloproteinase activity in urine of patients with renal cell carcinoma leads to degradation of extracellular matrix proteins: possible use as a screening assay. J Urol. 2003; 169: 1530-4. 
8. Slentz-Kesler KA, Hale LP, Kaufman RE: Identification and characterization of K12 (SECTM1), a novel human gene that encodes a Golgi-associated protein with transmembrane and secreted isoforms. Genomics. 1998; 47: 327-40.

9. Matsushita M, Thiel S, Jensenius JC, Terai I, Fujita T: Proteolytic activities of two types of mannose-binding lectin-associated serine protease. J Immunol. 2000; 165: 2637-42.
10. Guérin-Dubiard C, Pasco M, Mollé D, Désert C, Croguennec T, Nau F: Proteomic analysis of hen egg white. J Agric Food Chem. 2006; 54: 3901-10.

11. Algaba F, Akaza $H$, López-Beltrán A, Martignoni G, Moch $\mathrm{H}$, Montironi $\mathrm{R}$, et al.: Current pathology keys of renal cell carcinoma. Eur Urol. 2011; 60: 634-43.

\section{Correspondence address \\ Dr. Antonio Augusto Ornellas Department of Urology Instituto Nacional de Câncer Praça da Cruz Vermelha, 23} Rio de Janeiro, RJ, 20230-130, Brasil

E-mail: ornellasa@hotmail.com 